\title{
New occurrence and potential distribution of Anastrepha zacharyi (Diptera: Tephritidae) in the Eastern Amazon
}

\author{
Jefferson Bruno Carvalho Soares ${ }^{1}$ (D), Cezário Ferreira dos Santos Junior ${ }^{2 *}$ (D), \\ Leonardo de Sousa Miranda ${ }^{3}$ (D), Mauricio Sekiguchi de Godoy ${ }^{4}$ (D), \\ Miguel Francisco de Souza-Filho ${ }^{5}$ (D), Walkymário de Paulo Lemos ${ }^{6}$ (D), \\ Anderson Gonçalves da Silva ${ }^{1}$
}

\author{
${ }^{1}$ Universidade Federal Rural da Amazônia, Programa de Pós-Graduação em Agronomia, Belém, PA, Brasil. \\ ${ }^{2}$ Universidade do Estado de Santa Catarina, Programa de Pós-Graduação em Produção Vegetal, Lages, SC, Brasil. \\ ${ }^{3}$ Instituto Tecnológico Vale Desenvolvimento Sustentável, Belém, PA, Brasil. \\ ${ }^{4}$ Universidade Federal Rural do Semi-árido, Departamento de Fitossanidade, Mossoró, RN, Brasil. \\ ${ }^{5}$ Instituto Biológico, Secretaria de Agricultura e Abastecimento, Campinas, SP, Brasil. \\ ${ }^{6}$ Embrapa Amazônia Oriental, Laboratório de Entomologia, Belém, PA, Brasil.
}

\section{A R T I C L E I N F O}

\section{Article history:}

Received 08 September 2019

Accepted 27 December 2019

Available online 17 February 2020

Associate Editor: Sarah Oliveira

\section{A B S T R A C T}

The species Anastrepha zacharyi Norrbom has recently been recorded in the Amazon, however the species is subsampling in the biome. In this research, we report a new occurrence of $A$. zacharyi in the state of Pará and, through climate suitability modelling, present new possible distribution areas of the species in the Brazilian eastern Amazon.

\section{Keywords:}

Habitat

Insect pest

Modeling

Fruit fly

Fruit flies (Diptera: Tephritidae) are among the main challenges for world fruit production (Araujo et al., 2018), as the larvae of some species damage the quality of fruits, making their in natura commercialization unfeasible. In Brazil, among the economically important fruit flies, the genus Anastrepha Schiner stands out for the largest number of species potentially harmful to national fruit production (Zucchi and Moraes 2008). Due to the economic importance of the genus Anastrepha, many studies have been conducted in Brazil aiming mainly map its distribution, as well as the trophic relationship of these tephritids (Araujo et al., 2018; Silva et al., 2018; Sousa et al., 2017). However, despite the efforts of different research teams, some fruit fly species, such as Anastrepha zacharyi Norrbom, 2015 still lack basic ecological information.

In Brazil, A. zacharyi has been reported only in the state of Amapá (Adaime et al., 2016) and, from its recent description (Norrbom et al.,

\footnotetext{
* Corresponding author.

E-mail: agrosantos01@gmail.com (C.F. Santos Junior).
}

2015), little is known about its distribution and economic importance for fruit crops in the Amazon region. Therefore, this study expands the occurrence of $A$. zacharyi in the Brazilian Amazon and presents a Habitat Suitability Model (HSM) for this species, aiming to scientifically support future field research.

Between March 2017 and October 2018, a series of fruit fly collections (Diptera: Tephritidae) was carried out in Cametá, Pará, Brazil, aiming to increase the knowledge of the community of these insects in the region. To capture the insects, $30 \mathrm{McPh}$ ail traps were used, each one supplied with $400 \mathrm{~mL}$ of $5 \%$ hydrolyzed protein as attractive food and were distributed in urban, agricultural, and forest-fragment areas. Traps were examined and replenished weekly, and captured adult fruit flies were properly sexed, labeled, and packaged in vials with $70 \%$ ethanol. Subsequently, the specimens were sent to the Instituto Biológico (IB) in the state of São Paulo, where they were identified and deposited in the institution's collection. HSM was performed using the biomod2 package (Thuiller et al., 2009), through the R (R Core Team) software. 
The known occurrence points of $A$. zacharyi (Adaime et al., 2016; Norrbom et al., 2015) were used, including the new point recorded in this study $(\mathrm{N}=11)$.

Three pseudo-absence databases were defined containing 10 times the number of presences. Predictor variables were climate layers with the lowest autocorrelation: temperature seasonality (Bio4), annual temperature variation (Bio7), average temperature in the wettest trimester (Bio8), average temperature in the driest trimester (Bio9), precipitation seasonality (Bio15), precipitation in the wettest trimester (Bio16), precipitation in the driest trimester (Bio17), precipitation in the hottest trimester (Bio18), precipitation in the coldest trimester (Bio19), and altitude, provided by WorldClim (http: //worldclim.org) at a resolution of $\sim 1 \mathrm{~km}$. For construction of the models, we used the algorithms GLM, MAXENT, RF, FDA, and ANN.

For each algorithm, 10 runs were performed; in each run, $80 \%$ of the data were used for calibration and $20 \%$ for testing. The quality of the models was evaluated by the TSS index (Allouche et al., 2006),
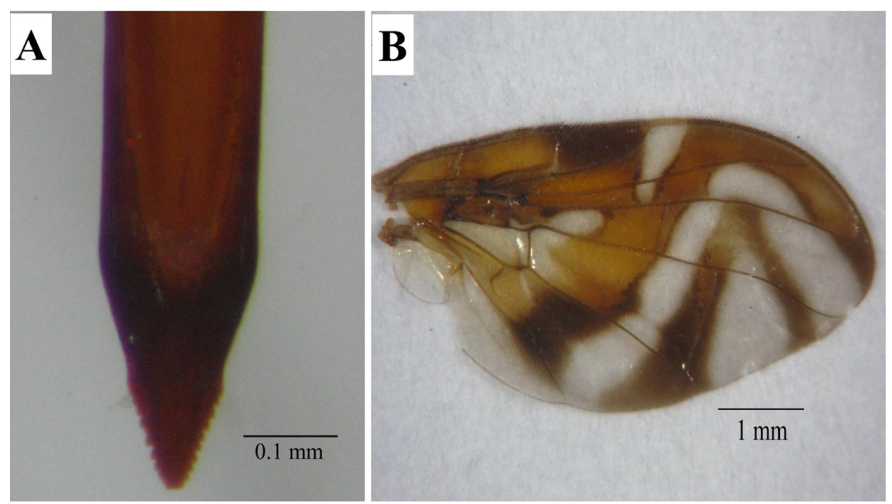

Figure 1 Adults of Anastrepha zacharyi. A. Detail of the aculeus. B. Wing region, frotal view. which was also used for the binarization process (transformation of presence-absence maps) and construction of the consensus map by the committee averaging method (Thuiller et al., 2009).

\section{Morphological identification of Anastrepha zacharyi}

The total number of Anastrepha females trapped during the study period was 923 , with one specimen identified as $A$. zaccharyi, which belongs to the fraterculus group and has the following morphological characteristics: specimens with the aculeus measuring $2.16-2.56 \mathrm{~mm}$ in length with apex gradually narrowing in triangular, serrated form (tip 0.20-0.27 $\mathrm{mm}$ long and 0.16-0.19 $\mathrm{mm}$ wide) (Figure $1 \mathrm{~A}$ ) and wings with all bands (costal, $S$, and inverted $V$ ), which may present the apex of the V-band linked or not to the S-band (Figure 1B) (Norrbom et al., 2015).

Therefore, this is the first record of occurrence of this species in the state of Pará, which expands to 29 the number of fruit fly species of the genus Anastrepha, known to occur in the region. However, we believe that other species have not yet been reported or described, possibly because the region has extensive areas with difficult-to-reach vegetation, which makes monitoring of these tephritids difficult.

\section{Potential distribution of Anastrepha zacharyi}

Regarding HSM, our results presented high TSS values (0.96), indicating accuracy of the models. The projections of the consensus map revealed a larger area of highly suitable habitats (suitability $>0.8$ ) for A. zacharyi located throughout the eastern portion of Amapá state, the Marajó archipelago mesoregion (including the northern end of the Xingú-Tocantins interfluvium), in addition to three isolated areas - one located northwest of Maranhão, one in the mesoregion of the city of Belém and northeast of the Pará state, and one between the states of Pará and Amazonas (Figure 2).

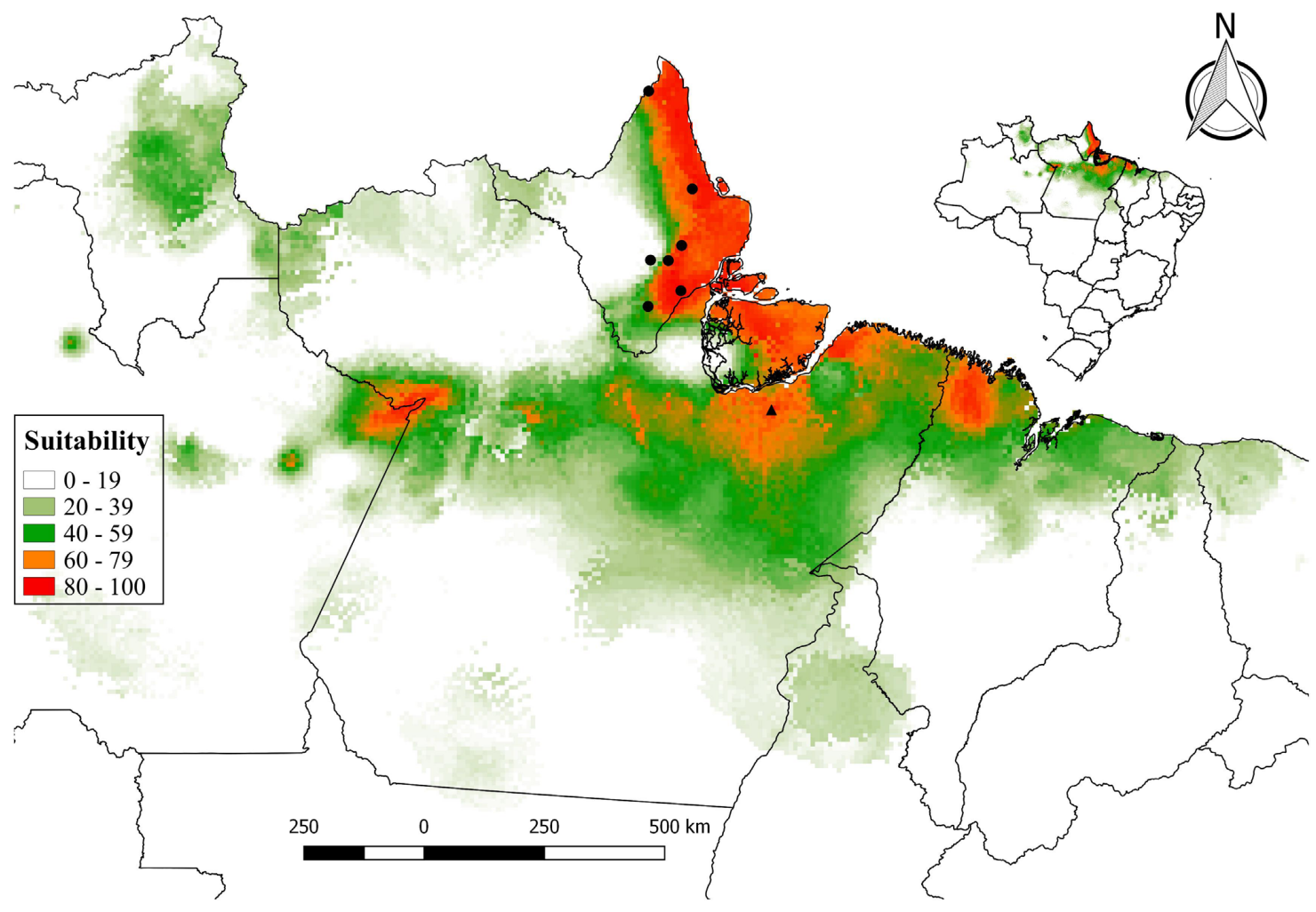

Figure 2 Potential distribution of Anastrepha zacharyi from Habitat Suitability Modeling plus its occurrence points (Literature Records =•); (New Record = $\mathbf{\Delta}$ ). 
Based on HSM, eastern Amazonia was the region most likely to have suitable habitats for $A$. zacharyi (Figure 2). However, due to the reduced number of recorded occurrence points of the species, it is possible that some locations of the Amazon region have been underestimated, which makes us believe that with the addition of new occurrence points of the species, the models will be improved and new areas may present good environmental suitability for $A$. zacharyioccurrence (Syfert et al., 2014). As the type locality of the species is Peru, is possible that the distributional pattern of it is continuous of Peru through the Amazon including the western Amazon rainforest.

We recommend, therefore, the intensification of field studies in areas that present high environmental suitability for A. zacharyi, aiming to broaden the knowledge of its bioecology and the enhancement of the models of species occurrence. Our results contribute to the development of knowledge about the diversity of fruit flies in the Brazilian Amazon and reinforces that $A$. zacharyi, under current climatic conditions, is predisposed to inhabit the eastern Amazon.

\section{Acknowledgements}

We thank the Coordenação de Aperfeiçoamento de Pessoal de Nível Superior (CAPES) for granting the PhD scholarship to the first author, which enabled the development of his thesis, of which this work is part. We also thank professors Antonio Rodrigues Fernandes and Rafael Coelho Ribeiro for their support in the development of this research.

\section{Conflicts of interest}

The author declares no conflicts of interest.

\section{Author contribution statement}

JBCS and CFSJ, data collection; JBCS and LSM, made the models of environmental suitability; MFSF and MSG, taxonomic identification;
WPL and AGS, development of the experiment. All authors contributed to the writing of the manuscript.

\section{References}

Adaime, R., Jesus-Barros, C. R., Uramoto, K., Norrbom, A. L., Zucchi, R. A., 2016. First Record of Anastrepha zacharyi Norrbom (Diptera, Tephritidae) in Brazil, and notes on its host plant and parasitoid. Proc. Entomol. Soc. Wash. 118, 636-640.

Allouche, O., Tsoar, A., Kadmon, R., 2006. Assessing the accuracy of species distribution models: Prevalence, kappa and the true skill statistic (TSS). J. Appl. Ecol. 43, 1223-1232.

Araujo, M. R., Uramoto, K., Ferreira, E. N. L., Mesquita Filho, W., Walder, J. M. M., Savaris, M., Zucchi, R. A., 2018. Fruit fly (Diptera: Tephritidae) diversity and host relationships in diverse environments estimated with two sampling methods. Environ. Entomol. 48, 227-233.

Norrbom, A. L., Rodriguez, E. J., Steck, G. J., Sutton, B. A., Nolazco, N., 2015. New species and host plants of Anastrepha (Diptera: Tephritidae) primarily from Peru and Bolivia. Zootaxa 4041, 1-94.

Silva, A. T., Silva, A., Santos, R. S., Sousa, M. D. S. M., Adaime, R., 2018. Levantamento de moscas frugívoras em dois municípios doestado do Acre, Brasil. Biotemas 31, 25-31.

Sousa, M. M., Martins, D. C., Fernandes, E. C., Ferreira, A. D. L., Araujo, E. L., 2017. Fruit flies (Diptera: Tephritidae) and their hosts in the municipality of Quixeré, state of Ceará, Brazil. Rev. Verde Agroecol. Desenvolv. Sustent. 12, 530-534.

Syfert, M. M., Joppa, L., Smith, M. J., Coomes, D. A., Bachman, S. P., Brummitt, N. A., 2014. Using species distribution models to inform IUCN Red List assessments. Biol. Conserv. 177, 174-184.

Thuiller, W., Lafourcade, B., Engler, R., Araújo, M. B., 2009. BIOMOD - A platform for ensemble forecasting of species distributions. Ecography 32, 369-373.

Zucchi, R. A., Moraes, R. C. B., 2008. Fruit flies in Brazil - Anastrepha species their host plants and parasitoids. Available in: www.lea. esalq.usp.br/anastrepha/ (accessed 17 September 2018). 